\title{
The Practical Exploration of the College Sports Public Service Platform in the Community of School-Enterprise Interests
}

\author{
Jiajia Li, Jun He \\ Southwest Petroleum University-Nanchong Campus, Nanchong, Sichuan,637000, China.
}

Keywords: School-enterprise interest community; College sports; Public service platform.

\begin{abstract}
China's campus enterprises have gradually become a community of interests, and its operation is closely connected with the direction of the development of universities. How should build system of perfect and reasonable configuration and scientific arrangement of physical education teaching plan, need a long-term and persistent exploration, this paper under the interests between the apparent deficiency, explores the problems existing in the university sports public platform construction, and puts forward the corresponding solutions. Strive to establish the new schoolenterprise cooperation mode, and make its reasonable devotion to the national fitness.
\end{abstract}

\section{Introduction}

With the deepening of the curriculum reform, education of colleges and universities focus gradually from the cultivation of the professional discipline talents to universal education of high-end talent changes, start from two aspects of subject education and quality education. Morality, intelligence, body, beauty and labor are the key direction of cultivating talents comprehensively. This paper starts from the perspective of reform of sports public service platform in colleges and universities, and probes into how sports education is better combined with overall fitness in the view of the school-enterprise interest community.

\section{University Sports Education Brief Introduction.}

Nowadays, higher education gradually loosened the barriers to entry, make most of the students can enjoy the higher education, corresponding, the infrastructure construction of colleges and universities also ushered in the development of good timing. Some colleges and universities build gymnasiums, swimming pools and so on, which provide the basic platform for the sports public education, and the sports construction of colleges and universities has begun to enter the stage of connotation promotion and popularization. [1] Besides, some colleges and universities have relatively concentrated human resources of education, and the comprehensive strength of sports talents is also well equipped. Most colleges also have sports majors, which can recruit students in advance. Sports gradually become an important factor of the consideration school comprehensive strength, also let in all kinds of sports has become an independent department of colleges and universities, the sports management department, they and the other is committed to supporting the university sports departments and organizations, constitute the university sports public management platform.

Not only that, physical education is not only responsible for the mission of the mission, but also the training of professional athletes, technical development and innovation of professional projects. In today's colleges and universities, students do not know much about the sports movement, and their enthusiasm is not high. [2] The school needs to take on the promotion of new projects and the popularization of traditional projects, such as increasing orienteering, climbing, frisbee and other courses, and adding certain assessment standards. Most of the institutions of higher learning to open a related management work, such as to establish special proprietary departments and personnel for the school sports assets management, in the school sports work for planning as well as the general facility maintenance and so on are carried out regular content. It can be said that a certain system has been formed. 


\section{The Theory of Sports Public Platform}

Today, the state encourages people to actively participate in sports and fitness programs to slow down the aging process and reduce the risk of cardiovascular disease.[3]But because of the population and sports don't correspond between infrastructure and the existing community gym facilities cannot meet the demand of most people's fitness, the site of the conflict problem, the for example old age group calisthenics are often in conflict with the requirements for the environment and residents, in the community fitness equipment type is not complete, and fitness person want to swim, swimming pool but remoter distance, etc. As the most concentrated resource, institutions with perfect facilities should assume this social responsibility and contribute to the construction of national sports public services.

In recent years, the idea from generation to achieve, born from the theory to be born, a long time, the reform of research scholars through the study of social sports resources sharing, and gradually find the balance between education and sports public services in colleges and universities, colleges and universities and also gradually grope out an effective way of operation, as the foundation of gradually realize college sports resources sharing has laid a solid foundation, let the colleges and universities to join in full fitness as soon as possible. In this way, the public can enjoy the convenience brought by the sports facilities and service products of colleges and universities, which is also a way to promote the effective utilization of resources"School-enterprise community"This concept is proposed by universities and enterprises based on common interests, which is derived from common cognition, and the cultivation of talents is organically integrated in a certain way. Aiming at the establishment of the sports public service platform, universities and enterprises are not exclusive, so it is also determined that this common whole has certain stability. The connotation of this organization is mainly concentrated in "Shared"On the second word,On the one hand, the cultivation of talents is Shared by both parties, and the cultivation process is unified. On the other hand, responsibility and power are highly unified, and results and responsibilities are Shared. Colleges and universities on the basis of this, managers need to after each semester curriculum arrangement, the basis of the inventory that colleges and universities can provide to the social resources, such as sports facilities, sports equipment, teachers and so on, which can estimate the school provide the appropriate resources, including two aspects of human resources and material resources, can according to the resources after the society, for the construction of social service system, make resources real people1's dose.

\section{Policy and Organizational Construction.}

Want to make the community of interests between colleges plan implementation in sports public platform construction, the school administration must shoulder their responsibilities, obligations, and clear their own needs from the social politics, economy, culture present situation to conduct a comprehensive and systematic trade-off and thinking, put forward the corresponding organization structure scheme. And as a government agency, it must be formulated in accordance with the rules and policy of the people's needs and ability in colleges and universities, making regulations of practical and operable, and the need to establish a responsibility system, guarantee and supervision in place, held accountable to the people. in this process, there are two system structure principle, a must for colleges and universities to provide service for society of the process as a core key, 2 . Must choose can use sports public service platform, such as choice enterprise outsourcing form, the process must ensure that the reasonable and lawful. Our school adopts the form of independent operation. In this case, the enterprise puts into a certain fund operation, and does not affect the normal school sports management work, the teacher and other resources sharing can also be realized. This comprehensive and systematic management mode makes the management of sports public service platform in our school run smoothly. 


\section{Fitness Management Method}

(1) Clear management objectives

The university sports public open platform, is win-win between the two sides in order to realize enterprise and school, enterprise departments must develop this as the foundation of all business activities, to earnestly implement the event planning, and other regular activities. At the same time, we should deal with the relationship of various departments within the club. Colleges and universities should put social responsibility before interest and assume the responsibility of social sports construction, while fitness clubs should optimize internal management and put students' needs before interests.But, disdainful of interests not represent profit not in the enterprise and the cooperation of colleges and universities, if there is no interest as the bridge and the link, universities and enterprises, there is no source of construction of sports public service platform and the power, can also be difficult to continue this work, not to mention the virtuous cycle. To sum up, it is necessary to grasp the boundary between the two, balance the interests of all parties, and finally provide convenient services for the public.

(2) Personnel allocation

Health club staff generally have their heads in the selected, enterprises can also choose under the same conditions preferential admit the teachers in colleges and universities, in the process of club operations, physical education teachers and students can undertake temporary training, to feel the degree of professional fitness club, and the practical results as an independent assessment of a part of the centralized accounting.

(3) The membership management

This work is the core link in the work, which is responsible for product marketing and publicity, planning and development of activities and adjustment of regular exercise time.[4]In addition, the enterprise should also do a good job of file establishment, member recruitment, activity registration and so on, and do well to the members of the physical quality work. This is also an important part of management.

(4) Site management

After various physical quality inspections members should continue to consider for their fitness goals to make a reasonable plan, and according to the plan, to determine the fitness goal, assign appropriate fitness coach, after complete personal training sessions. Managers for the adjustment of the site, you may need to actively coordinate, to fill in the information by members when joining for the reasonable arrangement of the venue, as well as the stipulated time, to prevent for venues such as reason, caused by the disputes and contradictions. Secondly, the trainer needs to adjust the fitness plan according to the actual effect.

(5) Commodity department and finance department.

The commodity department mainly provides professional fitness equipment, sports nutrition products, and the selection of fitness products for members. The finance department is mainly responsible for the warehousing management of funds, the assessment of the economic situation of enterprises, and the regular financial statements, as the basis for the management decisions. The work of the finance department and the commodity department should be extended and expanded in a timely manner, so as to further improve its functions, so as to make the management of the health club more advanced.

\section{Matters Needing Attention in the Operation of School-Enterprise Interest Community.}

(1) Balance the relationship between the two.

The school sports work and the fitness enterprise operation must be two parallel lines, cannot produce any additional conflicts and disputes.[5]On the one hand, should make full use of school resources, contribute to the mass fitness business, on the other hand, school administrators must ensure the sports work in normal students are not affected, do not put the cart before the horse. Therefore, the project should be analyzed and discussed comprehensively and systematically in terms of time, personnel, curriculum and equipment before the project is carried out. 
(2) Mutual management, coordinated operation

School and fitness clubs should coordinate with each other, work together to manage the corresponding fitness work, strict censorship member corresponding qualifications at the same time, the campus safety work in place, do not give an opportunity to criminals. Security must be important, before everything else. Colleges and universities must stop fraud and other illegal behaviors that threaten students' health. So, schools should strengthen security management.

(3) Improve the training system

Schools should formulate the perfect professional sports training system, and be included in the scope of academic assessment, and fitness clubs should fulfill their obligation to common training and guidance for students appointed professional fitness, assist complete sports school students training work, in the process, should value appraisal plan, clear training objectives, is committed to improving the students' professional quality.

(4) Unity of power and responsibility, coordination of all parties

When carries on the corresponding management, schools and enterprises must be clear to define responsibility and obligation, when conducting the club run, also should give full consideration to good health and the environment, the relationship between the campus sports culture, at the same time, school and club, must have a legitimate corresponding term of cooperation, convenient and year-end assessment, provide a reference for the next year whether to continue to cooperate. The school must implement the corresponding inspection management work, standardize the management, so that the club and the school can realize mutual benefit and reciprocity, reduce the occurrence probability of illegal situation.

(5) Face problems and communicate actively.

If the school needs to undertake sports events, it should actively communicate with the health club and coordinate the sports resources, especially the important teaching and competition. [6] It is also an important way to avoid conflict and avoid conflict. As institutions of higher learning, should clear university social responsibility, the social interests as an important yardstick for their work, only pay attention to social interests, really for the sake of each other, to make the long-term operation, the booming cooperation relationship. Communication is an important way to solve problems in practice. Both sides should actively face problems, solve problems and properly accomplish work and plan under special circumstances.

(6) All the best, cultivate talents

We talked about in the above, the two sides share common training talents, resources sharing of responsibility, so between the two sides should exert its advantages, common train sports professionals for the society, and actively related courses, such as aerobics, directional cross-country course, it is also important way to promote the development of social sports cultural undertakings.

\section{Conclusion}

The sports public platform of colleges and universities is an advantage sharing and the way of operation. Construction enterprises in the school, is to make both sides reciprocal symbiosis, let the school play the resource advantage, let companies take advantage of its management, thus hard for talent training and social sports resources sharing. The application of this method can also enable PE students to enter into practice as soon as possible, connect directly with the market, and guarantee the constant of social sports talents. at the same time, the enterprise also saves the corresponding funds, and opens up the market of fitness, thus providing a strong guarantee for the future and operation of the enterprise. It can be said that this cooperation mode meets the needs of both sides, which is also an important reason why cooperation can be carried out in the medium to long term.

\section{References}

[1]. Kaihao Deng, Quan Tao. The exploration of talent cultivation in higher vocational colleges from the perspective of school-enterprise interest community. [J]. Journal of Liuzhou Teachers College,2015,30(5):102-104. 
[2]. Yuzhi Gao, Guoquan Wang. Exploration and practice of modern apprenticeship based on schoolenterprise interest community.[J].Journal of North China Institute of Aerospace Engineering, 2015,25(6):51-53.

[3]. Chunhui Lv, Lihui Wang, Hao Liu. The practice and exploration of the establishment of schoolenterprise interest community -- taking food specialty as an example. [J]. SINO- FOREIGN EXCHANGE MONTHLY,2016(16).

[4]. Beilei Jiang. Based on the practical exploration of cooperative school-enterprise interest community -- taking the pet major as an example.[J].Chinese Journal of Animal Husbandry and Veterinary Medicine 2016(12):6-7.

[5]. Jun Zhang, Lei Xu. The application and practice of the three-level platform for the professional school-enterprise of dyeing and finishing technology in higher vocational colleges -- take the four years construction of dyeing and finishing technology of Suzhou Institute of Trade\& Commerce as an example.[J].Light Industry Science and Technology,2015(3):151-152.

[6]. Sumei Cai. Based on the construction and implementation of "embedded" school-enterprise interest community -- taking e-commerce as an example. [J]. Journal of Anyang Normal University,2016(2):143-145. 